\title{
Sexual Dysfunctions in Men: An Evolutionary Perspective
}

\author{
Menelaos Apostolou ${ }^{1}$
}

Published online: 18 July 2015

(C) Springer International Publishing 2015

\begin{abstract}
Successful sexual intercourse is a prerequisite for successful reproduction, a fact that translates into strong evolutionary pressures being exercised on mechanisms that regulate sexual functioning to work optimally. In effect, selection forces would remove from the gene pool any alleles that predispose for sexual dysfunctions, limiting their prevalence to very low levels. But this did not happen with epidemiological studies indicating that sexual dysfunctions are common, with approximately one in three men facing such a difficulty. This raises the question why evolutionary forces have allowed such variation in sexual functioning given its importance in reproduction. The present paper attempts to address this question by applying three evolutionary models on anthropological and historical evidence that depicts the ancestral human condition. It is argued that the high prevalence of sexual dysfunctions in men is predominantly explained by the mismatch between ancestral and modern environments, with selection forces not having sufficient time to optimize sexual functioning mechanisms to the demands of modern conditions. The proposed evolutionary framework is employed to derive predictions which are examined against the available evidence on sexual dysfunctions.
\end{abstract}

Keywords Premature ejaculation - Hypoactive sexual desire . Erectile dysfunction $\cdot$ Balancing selection $\cdot$ Ancestral neutrality $\cdot$ Polygenic mutation $\cdot$ Parental choice $\cdot$ Female choice

Menelaos Apostolou

m.apostolou@gmail.com

1 University of Nicosia, 46 Makedonitissas Ave., 1700, Nicosia, Cyprus

\section{Introduction}

In sexually reproducing species, sexual intercourse constitutes a prerequisite to reproduction. Accordingly, evolutionary forces have forged mechanisms such as sexual desire, sexual arousal, and orgasm to motivate intercourse to take place (Giles 2008; Toates 2014). The importance of sexual motivation for one's fitness (i.e., reproductive success) mandates that selection forces would not allow much variation in the workings of such mechanisms; that is, selection would have eliminated or have kept in low frequencies any alleles that impair sexual functioning. This predicts that sexual dysfunctions would be rare, a prediction which is not consistent with empirical evidence. A recently published paper employed anthropological evidence in order to reconstruct the ancestral human condition, and then to applied three evolutionary models in order to account for the high prevalence of sexual dysfunctions in women (Apostolou 2015). The purpose of the current paper is to use the same rationale in order to understand the high prevalence of sexual dysfunction in men.

More specifically, it is estimated that around $30 \%$ of adult men have at least one manifested sexual dysfunction (Lewis et al. 2004). In the USA, one study found the overall prevalence of sexual dysfunction to be $31 \%$, with premature ejaculation to be $21 \%$, erectile dysfunction to be $5 \%$, and low sexual desire to be $5 \%$ (Laumann et al. 1999). In a study of 13,618 men aged 40 to 80 years from 29 countries, Laumann et al. (2005) found early ejaculation to have the highest prevalence averaging $24.3 \%$ across regions, followed by erectile difficulties $(18.5 \%)$, and lack of sexual interest (17.8\%). Other prevalence studies have found similar high prevalence rates (for a review see Lewis et al. 2004).

It should be noted that the actual prevalence is probably higher, as most of the studies are based on self-reported evidence, where individuals may not be willing to admit that they 
face a sexual difficulty such as an inability to achieve an erection. It should be also considered the possibility that refusals to participate in these studies were more common among people, whose experience of sex was unpleasant, perhaps due to a sexual dysfunction, leading to those with the dysfunction being underrepresented.

This high prevalence of sexual dysfunctions in men raises the question of why selection forces have not eliminated from the gene pool any alleles that predispose for these difficulties. A life-history perspective can provide a possible answer. In this perspective, individuals have to solve different evolutionary problems in each stage of their lives. Consequently, there are different selection pressures exercised in different life stages, which may result in variation in the functioning of certain mechanisms (Hawkes and Paine 2006; Stearns 1992). From this viewpoint, older men have evolutionary problems to solve other than sexual reproduction, such as providing resources for their children and grandchildren. This translates into selection pressures on sexual functioning mechanisms to be much weaker in older age, which may, in turn, result in considerable variation in the functioning of these mechanisms in older men. To this, it should be added that evolutionary forces had been weaker on older men, particularly on men over 60 years, because, in ancestral times, many men did not pass the age of 60 years (see Gurven and Kaplan 2007). Overall, the life-history perspective predicts that age would be an important predictor of sexual functioning in men (Gray 2013; Gray and Garcia 2013); a prediction that is consistent with empirical evidence (Bancroft 2009; Laumann et al. 2005; Lewis et al. 2004).

Even so, sexual dysfunctions are also common in younger men. Evidence from several epidemiological studies find the prevalence of erectile dysfunction to be $1-9 \%$ in adult men below 40 years and ranging from $2-9 \%$ to $20-30 \%$ in the 40 59 age group (Lewis et al. 2004). Richters et al. (2003), in a representative sample of 10,173 Australian men, for the 16-19 age group, found the prevalence of lack of interest in having sex to be $24.5 \%$, premature ejaculation to be $15.3 \%$, and trouble keeping erection to be $4.3 \%$. For the $20-29$ age group, they found the lack of interest in sex to be $19.5 \%$, premature ejaculation to be $23.6 \%$, and trouble keeping erection to be $4.4 \%$, and for the $30-39$ age group, the lack of interest in having sex to be $22.1 \%$, premature ejaculation to be $25.6 \%$, and trouble keeping erection to be $5.1 \%$. An American study found low interest in sex to range from $14 \%$ for those $18-29$ years old to $17 \%$ for those 50 59 years old (Laumann et al. 1999). The prevalence of such dysfunction in younger men cannot be explained by the life-history perspective and remains evolutionarily puzzling. That is, it raises the question why selection forces have not removed from the gene pool any alleles that predispose younger men to sexual dysfunctions.
One possible answer is that there are no such alleles for selection forces to remove, and sexual dysfunctions are purely due to environmental factors (e.g., pollution and diet). Yet, evidence indicates that there is a genetic basis to sexual functioning; that is, part of the differences in sexual functioning between men is due to differences in their genetic make-up (Jern et al. 2009; Zion et al. 2006). But even if sexual dysfunctions were exclusively due to environmental factors, there is still the question of why selection forces have not made men resistant to these factors. Simply put, alleles which turn sexual functioning adversely susceptible to environmental factors would have been selected out from the gene pool. Finally, it can also be argued that sexual dysfunctions are due to psychogenic or medical conditions. Although it is true that conditions such as depression and diabetes can affect sexual functioning (Simons and Carey 2001), most men who suffer from a sexual dysfunction do not have a serious underlying medical condition or psychopathology (Carvalho and Nobre 2011; Wincze and Carey 2001).

There are three main evolutionary models that can potentially account for the prevalence of these dysfunctions. The purpose of this paper is to apply these models in order to understand the prevalence of premature ejaculation, erectile difficulties, and hypoactive sexual desire, which are the most common sexual dysfunctions in men (Wincze and Carey 2001). The argument will be developed in three stages: first, the different evolutionary models will be discussed; second, based on anthropological and historical evidence the evolutionary context will be reconstructed; and third, the relative contributions of each model will be discussed and predictions of the models will be examined against the available evidence.

\section{Evolutionary Models}

\section{Balancing Selection}

The predominant view on the prevalence of psychological disorders among evolutionary psychiatrists and evolutionary psychologists is the balancing selection model (Barrantes-Vidal 2004; Longley 2001; Wilson 1998). In the frequency-dependent selection aspect of the model, the fitness of alleles which predispose for a dysfunction increases as they become rarer. Thus, equilibrium is reached where both alleles that predispose for a given dysfunction and those that do not co-exist (Morris and Watson 2011). For instance, Mealey (1995) argued that psychopathy persists in the population at a low frequency for this exact reason. That is, individuals with this trait increase their fitness considerably by exploiting and taking resources from others, but this trait is less effective when it becomes common in the population and others become more vigilant of it. 


\section{Polygenic Mutation}

In order for an individual's genetic material to pass to future generations, it needs to copy itself multiple times, which means that the human genome is susceptible to copy errors or mutations. Mutations usually decrease fitness, so evolutionary forces remove them from the genome. But this process takes time, which constitutes a function of how harmful a mutation is; that is, it takes longer for less harmful mutations to be removed from the population. For example, it has been estimated that a mutation causing a $1 \%$ reduction in fitness will pass through approximately 100 generations before it is eliminated from the population (García-Dorado et al. 2003).

The main idea here is that the heritability in these traits is due to a large number of harmful alleles which are individually very rare at any given locus, but which are collectively common across loci (Keller and Miller 2006). There is some evidence in favor of this model for serious mental conditions such as schizophrenia (Sipos et al. 2004).

\section{Ancestral Neutrality}

Another possibility is ancestral neutrality: alleles for traits which are maladaptive in a modern post-industrial context may not have been equally maladaptive or not maladaptive at all in ancestral environments. To use one example, it has been argued that individuals with schizophrenia living in ancestral times were valued as shamans and were not socially ostracized as it is the case today (Polimeni and Reiss 2002). In this respect, alleles that increase the risk of sexual dysfunctions in a modern post-industrial context may not have had the same effect in ancestral environments.

The three models presented above can potentially explain the variation in sexual functioning in men. Mechanisms that regulate sexual functioning have been shaped by evolutionary forces in ancestral human environments. Consequently, the contribution of each force in shaping-specific aspects of sexual functioning depends on the ancestral conditions that determined the selection pressures exercised on sexual function mechanisms. In order to be able to understand the relative contributions of each model in sexual functioning, a reconstruction of ancestral human condition is required.

\section{Ancestral Context and Male Reproductive Success}

Our genus Homo appeared on earth approximately 2 million years ago, and for most of this period, our ancestors were living in small bands which based their subsistence on hunting and gathering (Lee and Devore 1968). Approximately 10,000 years ago, the agropastoral revolution took place, which resulted in the eventual transition of most human societies to a sedentary life and subsistence based on agriculture and animal husbandry (Bellwood 2004). Thus, most of human evolution took place in a pre-industrial context where subsistence was based on hunting and gathering and on agropastoralism (Lee and Devore 1968; Tooby and Cosmides 1990).

Accordingly, in order to understand the evolution of mechanisms which regulate sexual functioning, the identification of selection forces that have shaped them is necessary. These demands, in turn, demand knowledge of the patterns of mating in ancestral pre-industrial societies. Ancestral foragers did not leave behind any written records, but the anthropological record on modern hunting and gathering societies can be a useful source of information. The way of life of modern foragers approximates the way of life of ancestral ones, meaning that the typical patterns of mating in the former are likely to reflect the typical patterns in the latter (Ember 1978). In the same vein, the anthropological record of modern agropastoral societies can be used to reconstruct the way of life in ancestral agropastoral societies. Nevertheless, many ancestral agropastoral societies left behind written documents which constitute a valuable source of information on the human condition in the later period of human evolution.

Anthropological and historical evidence indicates that in a pre-industrial context there are three main ways for a man to gain sexual access to a woman, a typical one being through her parents. More specifically, in a pre-industrial context, mating is regulated with arranged marriage being the most common type of long-term mating (Broude and Green 1983; Stephens 1963). In more detail, one study collected evidence on mating patterns from a sample of 190 contemporary foraging societies (Apostolou 2007). It was found that the most frequent mode of long-term mating (in approximately $70 \%$ of cases) was arranged marriage, where parents choose spouses for their children. A subsequent study revealed similar patterns in contemporary pre-industrial societies, which base their subsistence on agriculture and animal husbandry (Apostolou 2010). Similarly, one study coded for the mating patterns of 16 historical agropastoral societies (Apostolou 2012). It was found that in all societies but one, the primary mode of long-term mating was arranged marriage, where fathers and other male relatives dominated marriage arrangements and daughters were controlled more than sons.

In this context, the primary way for a man to gain access to the reproductive capacity of a woman is through her parents. If parents approve him as a husband for their daughter, they grant him the right to have sexual access to her, which is usually exercised irrespectively of the woman's wishes; this deal is usually sealed with the payment of the bridewealth, (Goody and Tambiah 1973). In general, in most societies until recently (and in many contemporary societies), women had no legal grounds to resist sexual advances from their husbands, as forcing sex on one's wife was not considered illegal (Bergen 1996; Russell 1990). 
A second way is for a man to address women directly. In particular, in a pre-industrial context, there is considerable space for women to exercise choice. To begin with, they can engage in sexual relationships before their parents arrange a marriage (Apostolou 2014). Women can also exercise mate choice in extramarital relationships, which is found in almost all pre-industrial societies (Broude 1980). Last but not least, women can exercise choice in later marriages when they are more independent from their parents or their parents are absent due to death or because they are physically weak to impose their will (Apostolou 2014). In sum, there are different instances in which a man can directly attempt to persuade a woman to have sexual intercourse with him.

A third way is for a man to force sex on a woman (Thornhill and Palmer 2000). In most pre-industrial societies, rape is reported to take place in times of peace (Apostolou 2013). Also, in many societies, wars and raids are organized against neighboring groups in an attempt to get their resources, one being women. For instance, among the Yanomamo hunters and gathers in South America, frequent raids are organized against neighboring groups with the objective to get or force sex on their women (Chagnon 1992). In later stages of human evolution, there were large scale wars with women being one of the spoils of wars (Apostolou 2013). As a consequence of this war effort, there were a considerable number of female slaves that were used not only for physical labor but also for sex. For instance, in Ancient Rome wealthy men had many female slaves who were used as sexual outlets (Meltzer 1993). In more recent times, in North America, farm owners maintained a large number of black slaves to work in the fields. Forcing sex on female black slaves was not uncommon, and children were often the outcome of these relationships (Meltzer 1993).

The key insight derived from the anthropological and historical records is that during the period of human evolution, and particularly during its later stages, female choice had been a weaker selection force than it is today in postindustrial societies. In most cases, neither the consent nor the sexual satisfaction of women was a primary concern for men: Mate-seekers did not have to ask for consent or to sexually satisfy their mates in order to persuade them to marry them; husbands did not have to ask for consent or to sexually satisfy their wives to have sex with them; warriors did not ask for consent or need to sexually satisfy their victims; same for masters and their female slaves. Note that it is argued here that the sexual satisfaction of a man's wife is less of a concern in a preindustrial context than in a post-industrial context and not that this is not a concern; for instance, in both contexts, men need to satisfy their partners in order to reduce the risk of cuckoldry. The three evolutionary models applied to this evidence can provide us with useful insights on the prevalence of the most common sexual dysfunctions in men.

\section{The Relative Contributions of Each Evolutionary Model}

\section{Premature Ejaculation}

\section{Prevalence and Symptoms}

Premature ejaculation occurs when a man experiences orgasm soon after sexual activity and before he wishes it (Wincze and Carey 2001). There has been, however, some disagreement over how much time the 'soon after' specifically. Masters and Johnson (1970) avoided indicating a specific time period and suggested instead that premature ejaculation be diagnosed when a man "cannot control his ejaculatory process for a sufficient length of time during intravaginal containment to satisfy his partner in at least 50 percent of the coital connections" (p.92). On the other hand, the DSM-5 places a stringent time criterion of approximately 1 min following vaginal penetration (American Psychiatric Association 2013).

The prevalence of premature ejaculation depends on how stringent the time criterion is. Still, across different cultures about $20-30 \%$ of adult men report concerns about how rapidly they ejaculate (Bancroft 2009; Laumann et al. 2005; Laumann et al. 1999; Lewis et al. 2004). This turns premature ejaculation to be one of the most frequent sexual dysfunctions (Wincze and Carey 2001), with men suffering from it reporting emotional and relationship distress, and some avoid engaging in intimate relationships to avoid embarrassment (Barnes and Eardley 2007).

\section{Evolutionary Account}

In a pre-industrial context, and thus most likely in ancestral human societies, female choice is weak indicating that, whether one's wife, rape victim or slave remained sexually satisfied, is likely to be a secondary concern for most men. Therefore, the time period between initiation of sexual intercourse and ejaculation would had little fitness consequences, meaning that selection forces would allow considerable variation in this trait (see Brooks et al. 2005), with many men climaxing relatively quickly, not allowing sufficient time to sexually satisfy their partners. Another way to put it is that men who would ejaculate relatively quickly after the initiation of intercourse, giving less sexual satisfaction to their partners, would not be much worse-off than those who ejaculate in later time, giving more sexual satisfaction to their partners. As a consequence, both predispositions would remain in the population.

On the other hand, in a post-industrial context, where female choice is much stronger, inability to satisfy one's partner is likely to cause considerable strain in intimate relationships (Carson and Guun 2006). This would lead many men and couples to seek help, and eventually ejaculating too quickly to provide sexual satisfaction to one's partner to be classified 
as a sexual dysfunction. Still, this dysfunction is not a genuine biological dysfunction, but it is mainly the case that the mechanism that regulates the latency of orgasm has not been optimized for the demands of the modern environment. In different words, reaching orgasm relatively quickly had little fitness consequences during ancestral times for selection to act against this predisposition. Accordingly, the ancestral neutrality model can account for the high prevalence of premature ejaculation in men, with the discrepancy between modern and ancestral environments explaining why this is considered to be a dysfunction.

\section{Predictions and Evidence}

One prediction that follows from the model is that in the majority of cases, an underlying psychopathology or a biological problem will not be a predictor of premature ejaculation. That is, most men who suffer from this dysfunction will be mentally and biologically healthy. Consistent with this, studies have found that medical problems such as vascular diseases are weak or no predictors of ejaculation latency time (Laumann et al. 2005; Wincze and Carey 2001). For instance, an Italian study of 12,558 men found no association between premature ejaculation and hypertension, cardiopathy, hypercholesterolemia, and peripheral or central neuropathy (Fasolo et al. 2005). In the same vein, studies have found that psychological factors such as anxiety and depression are weak predictors of premature ejaculation (Carson and Guun 2006; Strassberg et al. 1990 but see McCabe 2005).

The model further predicts that premature ejaculation is relatively independent of a man's age. In particular, if premature ejaculation was relatively neutral in the ancestral past, evolutionary forces working on this trait would not vary across a man's reproductive years; that is, there would be weak selection pressures on the ejaculation latency time across a man's sexual life span. Therefore, this trait would not have been adjusted by selection forces to work differently according to age. Consistent with this, empirical studies do not find any association between age and premature ejaculation (Dunn et al. 2002; Laumann et al. 1999; Richters et al. 2003).

In a context where female choice is weak, the difference in fitness between alleles that predisposes a man to ejaculate relatively early after the initiation of intercourse, and alleles that predispose a man to ejaculate relatively late after the initiation of intercourse, would be small, so selection forces may maintain all alleles in the population. Accordingly, in this model, evolutionary forces allow a high frequency of alleles that predispose men to ejaculate relatively early. This predicts that there will be specific alleles that predispose for premature ejaculation. In accordance with this prediction, one study found that polymorphism in the serotonin transporter promoter region (5-HTTLPR) is associated with ejaculation latency time (Janssen et al. 2009). A meta-analysis found significant associations between the risk of premature ejaculation and 5HTTLPR polymorphism (Zhu et al. 2013). Furthermore, another study found that polymorphism in the dopamine transporter gene (DAT1) is associated with premature ejaculation (Santilla et al. 2010 see also Safarinejad 2011).

A related prediction is that part of the variation in the ejaculation latency time between men is explained by differences in their genetic make-up. That is to say, the ejaculation latency time should demonstrate a positive heritability. Consistent with this, a study of 1196 Finnish male twins estimated the heritability of premature ejaculation to be 0.28 (Jern et al. 2007), while a subsequent study of 2633 Finnish twins estimated the heritability of pre-mature ejaculation to be around 0.30 (Jern et al. 2009).

Selection forces would be relatively weak in shaping how quickly a man would ejaculate after initiation of intercourse, but would be very strong on men who ejaculate before initiation of intercourse as in this case conception cannot take place. This predicts that the prevalence of ejaculation before penetration would be very low. In line with this prediction, one Finnish study on premature ejaculation has found that $0.5 \%$ of participants in the sample reported almost always to ejaculate before initiation of intercourse, $1.1 \%$ in more than half of the times before initiation of intercourse, and $5.4 \%$ reported to ejaculate before initiation of intercourse about $50 \%$ of the times (Jern et al. 2007). Another Finnish study found the prevalence of ejaculating before initiation of intercourse almost always to be $0.3 \%$, in more than half of the times to be $0.7 \%$ and in about half of the times to be $2.6 \%$ (Jern et al. 2009).

The model predicts further that premature ejaculation will be found across different human cultures. That is, mechanisms that regulate the ejaculation latency time have been shaped by selection forces in the ancestral human context, and thus, they have come to characterize the entire human species rather than individual societies. Consistent with this, Laumann et al. (2005) found a high prevalence of the dysfunction in 29 countries in their sample, with prevalence rates across different world regions ranging from 12.4 to $30.5 \%$.

\section{Erectile Dysfunction}

\section{Prevalence and Symptoms}

Erectile dysfunction refers to partial or complete inability to attain, or to maintain, an erection long enough for intromission and subsequent sexual activity. This disorder may also involve a lessened or absent sense of excitement and pleasure (American Psychiatric Association 2013; Wincze and Carey 2001). Approximately $13-21 \%$ of men age between 40 80 years complains for occasional erection problems; frequent erection problems in men younger than 40 years are approximately $2 \%$ in prevalence while for those over $60-70$ range 
the prevalence is 40-50\% (American Psychiatric Association 2013; Bancroft 2009; Laumann et al. 2005; Laumann et al. 1999; Lewis et al. 2004).

\section{Evolutionary Account}

Not being able to achieve or to maintain an erection long enough to reach orgasm has considerable fitness consequences in a pre-industrial context, as it would make conception impossible. That is to say, there would be strong selection pressures on any alleles that predispose for such a dysfunction in men. Consequently, selection forces would allow little variation in erectile functioning, especially among younger men for whom sexual reproduction is a primary objective. Nevertheless, the modern environment may give rise to evolutionary novel factors that are likely to negatively impair erectile functioning for which selection did not have sufficient time to adjust the mechanisms involved.

One such factor is the presence of strong female choice in modern post-industrial societies (Buss 2003). In particular, the need for men, in the vast majority of cases, to gain consent from their partners to have sexual intercourse and the need to satisfy their partners sexually are evolutionary novel situations. Accordingly, men in a post-industrial context face the challenge of performing well in sexual intercourse, a challenge that was not present in the past as their wives, victims, and slaves would not have abandoned them if they did not do so.

This is likely to cause many men to experience performance anxiety, which in turn will negatively affect their performance resulting in an inability to achieve or to maintain an erection. Thus, in this respect, selection forces did not have time to build resistance to performance anxiety since this is a relatively new phenomenon and our ancestors were unlikely to have come across it frequently. To put it another way, the tendency to feel performance anxiety is a mismatch with the modern environment - such that men, confronted with a society in which women increasingly demand more sexual satisfaction, would experience performance anxiety.

Overall, ancestral neutrality can potentially explain part of the prevalence of erectile dysfunctions, especially among younger men. That is, factors that may affect erectile functioning today had been neutral, not present, or much less important in ancestral human environments where sexual functioning mechanisms were optimized by evolutionary forces.

\section{Predictions and Evidence}

The model predicts that performance anxiety constitutes a strong predictor of erectile dysfunction. Masters and Johnson (1970) suggested that anxiety about sexual performance was the most important immediate cause of sexual dysfunction. One study found performance anxiety to be the main predictor of erectile dysfunction as well as other aspects of sexual dysfunction including orgasm and desire, even after controlling several factors such as lifestyle and relationship dynamics (McCabe 2005). Other studies produced similar results (Liu 2002; Loudon 1998; Shires and Miller 1998). In general, it is agreed that in young males, erectile dysfunction is mostly due to a psychogenic etiology such as anxiety, with biological causes becoming increasingly more important with age such that older men have more biological causes and younger men have more psychogenic causes (Caskurulu et al. 2004).

The model does not predict that variation between men in sexual functioning will be due to alleles that directly affect sexual functioning. Nevertheless, considerable heritability is expected in variation in erectile dysfunction. In particular, as anxiety level is predicted by personality (Wilt et al. 2011), differences in personality between men will result in different anxiety levels, leading in differences in erectile functioning. But since personality has high heritability (Plomin et al. 2012), the heritability of erectile functioning will also be high as differences in sexual functioning between men will be partially due to their genetic differences that predispose for different personality types. Similarly, erectile dysfunction, especially in middle and older age men, is also caused by medical factors such as diabetes and a heart condition that have a genetic basis (Plomin et al. 2012). This will also result in positive heritability for erectile dysfunction.

Overall, significant heritability in erectile functioning is expected, with most of the heritability in younger age to be due to heritability in personality and in later age to be due to heritability in medical conditions. In accordance with this, one study that employed 890 monozygotic and 619 dizygotic pairs of twins estimated the heritability of the liability for dysfunction in having an erection to be 0.35 and of maintaining an erection to be 0.42 (Fischer et al. 2004). This is surprisingly close to the heritability of personality, which is about 0.40 (Plomin et al. 2012). However, more studies are required in order to test specifically whether this heritability is due to heritability coming from personality.

The model predicts that erectile dysfunction, especially among younger men, will be caused predominantly by evolutionary novel factors as selection forces did not have time to adjust the mechanisms involved in this domain to modern conditions. One such case is the use of condoms, which is evolutionarily novel, and it is likely to have a negative impact on sexual organs that have evolved to function without it. Accordingly, a study of sexually active adolescents found a prevalence of $13 \%$ in erectile dysfunction, which almost doubled to $25 \%$ with the use of condoms Mussachio et al. (2006).

Moreover, religious values that emphasize anxiety and guilt over sex could also be viewed as potential factors (see Cowden and Bradshaw 2007), insofar as the emotional association with sexual desire and activity are evolutionarily 
novel. Similarly, pornography is another evolutionary novel factor that may have an effect on men's sexual functioning. For example, excessive porn consumption reduces romantic relationship satisfaction (Lambert et al. 2012), and it is linked with greater endorsement of, and more frequent participation in, extra-marital relations (Wright 2013). In addition, other evolutionary novel environmental conditions such as air pollution, high levels of stress, unemployment, and overpopulation may likewise negatively affect sexual functioning. The effect can be indirect. For instance, the modern diet is considerably higher in sugars and fats than the ancestral diet, while people have less physical exercise than they used to have when working in the field or when hunting and gathering (Cordain et al. 1998; Eaton 2006). The consequence of this is a high prevalence of diabetes and heart conditions, which in turn have a negative impact on sexual functioning especially in later age (Lewis et al. 2004). Therefore, in some cases, sexual dysfunction has been caused by a medical condition, which is nonetheless due to the mismatch between ancestral and modern environments.

\section{Hypoactive Sexual Desire}

\section{Prevalence and Symptoms}

Following the DSM-5 male hypoactive sexual desire disorder refers to "persistently or recurrently deficient (or absent) sexual/erotic thoughts or fantasies and desire for sexual activity" (American Psychiatric Association 2013). For a diagnosis to be given, the symptoms need to have persisted for a minimum duration of approximately 6 months and cause distress to the individual. Although the prevalence rates vary widely depending on country and method of assessment, it is estimated that approximately $6 \%$ of men in the ages of 18-24 years and $41 \%$ of men in the ages of $66-74$ years face sexual desire problems (American Psychiatric Association 2013; Bancroft 2009; Laumann et al. 2005; Lewis et al. 2004).

\section{Evolutionary Account}

In a pre-industrial context, a man can increase his reproductive success by marrying a woman, having children with her, and investing heavily in these children. A man can also increase his reproductive success by having sex with many different women and investing little in them and their children. Both strategies can be successful; in the first one, a man can have a few children with very good chances of survival and reproduction, while in the second strategy he can have many children with fewer chances of survival and reproduction (Buss 2003; Buss and Schmitt 1993; Gangestad and Simpson 2000). Consequently, in both situations, a man is likely to leave an equal number of offspring who reach sexual maturity.
Another way to put this is that there are at least two evolutionary niches, one for men who invest heavily in a few women and their children and one for men who invest little in many women and their children. Accordingly, two mating strategies are likely to evolve that fill each niche, namely, a long-term (i.e., invest in a few women and have children with them) and a short-term one (invest little in many women). When a species occupies multiple niches, a polymorphic equilibrium (i.e., two or more distinct specializations) is usually more optimal than a monomorphic one (i.e., a single specialization) as specialists are more efficient than generalists (Wilson 1994 see also Figueredo et al. 2009). This means that although most men have the capacity to follow both strategies, some will tend to specialize in one and some in the other.

Balancing selection will determine the relative frequencies of each morph in the population. In particular, men who follow a short-term strategy (i.e., strive to get casual partners) gain reproductive benefits and pay little cost in terms of parental investment, so selection will favor them. But as they become more common in the population, parents, husbands, and women will become increasingly aware of their presence, and they will be more likely to guard themselves. That is, sexual contact is likely to commit a woman's parental investment to a child through pregnancy, so it pays for women and their parents to screen men, and accept as husbands and inlaws, respectively, only those who are willing to commit in a long-term relationship (Apostolou 2014; Trivers 1972). In the presence of a high prevalence short-term morph, women and their parents will be more cautious in accepting men's offers, and parents will chaperone their daughters more carefully. In addition, men will face a higher risk of cuckoldry in the presence of a high prevalence of the short-term male morph, and so, they will guard their wives more closely. This means that reproductive payoffs of this morph will decline and the frequency of the long-term mating strategy morph will increase, as this is the one that now will be favored by selection forces. Eventually, equilibrium will be reached with both morphs existing in the population.

Men who follow a long-term strategy increase their fitness by having children with their long-term partners and investing heavily in them (Buss 2003). However, in order to do so, a continuing sexual interest towards one's partner and a high libido are not necessary since long-term frequent sexual intercourse is not required for conception to take place (Klusman 2002). On the other hand, a high level of sexual desire is likely to interfere with men's long-term strategy because it will motivate them to divert their resources from raising their children to the effort of attracting sexual partners (see Fisher 1998; Gangestad and Simpson 2000).

Accordingly, men who follow a long-term reproductive strategy are expected to have a lower level of sexual desire than men who follow a short-term one. They are also expected to experience periods of low sexual desire after establishing a 
long-term relationship and having children in order to divert the bulk of their effort in investing in these children. Subsequently, many of these men will report low levels of sexual desire, accounting for part of the prevalence of hypoactive sexual desire. The evolutionary niche for a longterm mating strategy in a post-industrial context is qualitative different from the ancestral one, as in the former, for the reasons explained above, the expectation for sexual satisfaction of one' wife is higher than in the latter. Thus, low sexual desire in a modern context may cause relationship strains and consequently be labeled as a dysfunction.

\section{Predictions and Evidence}

Sexual desire has been shaped by selection forces in the ancestral human context, and thus, the optimization of this mechanism would tend to characterize our species. Therefore, it is expected that hypoactive sexual desire will be present across different cultures. Accordingly, Laumann et al. (2005), in a cross-cultural study, found lack of sexual interest in men across different world regions to range from $12.5 \%$ (Northern Europe) to $28 \%$ (Southeast Asia).

It can also be predicted that in societies where the sexuality of women is strongly regulated the long-term mating strategy morph would be more prevalent, and consequently, men in these cultures will exhibit lower sexual desire than men in cultures where it is more loosely regulated. The reason is that in the former the environmental context will favor a higher frequency of long-term mating strategy morph. Where control over women is higher and there are limited opportunities for casual sex, lovers are more heavily punished, while those who follow a long-term mating strategy are less likely to face frictions in their relationships if they do not satisfy their partners. Consistent with this, Laumann et al. (2005) found that low sexual desire in men is in lower prevalence in Northern Europe $(12.5 \%)$ where the sexuality of women is less strictly regulated than in Middle East (21.6 \%), East Asia (19.6\%), and Southeast Asia (28\%) where the sexuality of women is more strongly regulated.

A further prediction that follows from the model is that differences in the level of sexual desire between men are, to a considerable extent, explained by genetic differences between them. In accordance with this prediction, one study found evidence that polymorphism in the dopamine D4 receptor gene is associated with variation in sexual desire (Zion et al. 2006). Nevertheless, heritability studies are required to test specifically this prediction.

For men who follow a long-term mating strategy, there will be weaker selection pressures on their erectile functioning and on the timing between initiation of sex and climax. In particular, for men who follow a short-term mating strategy, an erectile difficulty means losing an important reproductive opportunity, usually for good, placing them at a competitive disadvantage over other men who follow the same strategy. But for men who follow a long-term mating strategy, instances of erectile dysfunction will have little reproductive consequences, as their partners are continuingly available for sexual intercourse. Consequently, there is stronger selection pressure on the former than on the latter's ability to achieve and maintain an erection.

In the same vein, men who follow a short-term mating strategy need to emphasize more on giving pleasure to a woman; but men who follow a long-term mating strategy need to emphasize more on giving commitment to a woman. Therefore, there is stronger selection pressure on the former than on the latter to increase the ejaculation latency time to allow more time for the sexual satisfaction of their partner. This suggests that sexual dysfunctions will predominantly characterize the long-term morph; thus, men who follow this strategy are likely to have more than one such dysfunction. Accordingly, it is predicted that there will be comorbidity between low sexual desire and erectile dysfunction and premature ejaculation.

In accordance with this prediction, one study found that the co-presence of low sexual desire and erectile dysfunction to be common (Corona et al. 2004). Similarly, another study employed a sample of 5255 men aged 18-75 years from Portugal, Croatia, and Norway and found that those with low sexual interests also reported other sexual difficulties, the most common being erectile dysfunction in approximately half of the cases (Carvalheira et al. 2014). Similarly, a nationally representative Swedish survey found that $45 \%$ of the men with low sexual interest also had erectile complaints and $26 \%$ faced early ejaculation (Fugl-Meyer and Fugl-Meyer 1999).

It is also predicted that in the majority of cases of the hypoactive sexual desire there will not be an underlying medical or psychogenic cause. Accordingly, although psychogenic factors such as depression and anxiety or medical pathologies may negatively influence sexual desire (Bancroft 2009; Basson and Schultz 2007; Hartmann 2007), these will not be the primary etiologies in the majority of men who experience hypoactive sexual desire. Consistent with this, a study of Portuguese men found that general psychopathology and medical pathologies do not have a central role in male sexual desire (Carvalho and Nobre 2011). The researchers concluded that psychopathology and medical problems may be vulnerability factors for low sexual desire only when they interact with other factors such as dysfunctional cognitive processing or relationship dynamics.

\section{Severe Cases and Polygenic Mutation}

Polygenic mutation is likely to account for a small proportion of the prevalence of sexual dysfunctions in men. In particular, genetic mutations can push mechanisms 
involved in sexual functioning to operate at levels that are below or above what is now or was optimal in an ancestral context. Evolutionary forces would remove these mutations from the population, but this would require some time and during this time new mutations will arise (Keller and Miller 2006). Thus, at any given point in time, there will be a few men who face severe sexual dysfunctions.

This predicts that such cases will be rare, that is there will be very few men who can never achieve an erection, who have no sexual desire at all, and who ejaculate before initiation of sexual intercourse. As discussed above, one Finnish study found only $0.3 \%$ of the participants to almost always ejaculate before initiation of intercourse (Jern et al. 2009). Similarly, Laumann et al. (2005) found an overall prevalence of the lack of sexual interest to be around $18 \%$, but less than $3 \%$ of participants indicated that they frequently experienced lack of sexual interest. In the same vein, the prevalence of erectile difficulties was $18.5 \%$, but only around $3 \%$ of participants reported this problem to occur frequently.

One prediction that can be derived from the evolutionary framework is that there will be asymmetry in sexual dysfunctions. More specifically, if a man has no sexual desire at all, he will suffer a much higher fitness cost than if he experiences very high levels of sexual desire. That is, a man with low sexual desire will not be motivated to seek sexual intercourse suffering reproductive losses, while a man who constantly seeks sexual intercourse will also suffer costs (e.g., from angry husbands and sexually transmitted diseases), but not as high as the former since frequent sexual intercourse would lead to some reproductive success. Likewise, a man would suffer considerable reproductive costs if he is not able to achieve an erection at all, but much less so if he achieves an erection with the slightest stimulation. Similarly, a man will suffer substantial fitness costs if he has an orgasm as soon as he is stimulated than a man who achieves orgasm much after initiation of sexual intercourse.

This indicates that selection forces in men are stronger on the left tail of the distribution (e.g., very low sexual desire) than on the right tail of the distribution (e.g., very high sexual desire). In effect, selection forces will eliminate much faster from the gene pool any mutations for abnormally very low sexual functioning than for abnormally very high sexual functioning. This predicts that at any given point in time there will be more men suffering from, for instance, abnormally high levels of sexual desire than men suffering from abnormally low levels of sexual desire. Presently, there is limited research on the right end of the distribution (Kaplan and Kruger 2010) and no systematic attempt to compare the two tails. Accordingly, this prediction needs to be investigated by future research.

\section{Generalized Versus Situational Dysfunction}

The arguments developed above refer to generalized dysfunctions, i.e., dysfunctions which are not limited to certain types of stimulation, situations, or partners (American Psychiatric Association 2013). That is, the proposed evolutionary framework aims to account for the reasons why men face sexual difficulties such as premature ejaculation across different types of stimulation, situation, and partners.

However, it should be noted that a dysfunction can be situational, i.e., arising with certain types of stimulation, situations, or partners (American Psychiatric Association 2013). Situational sexual dysfunctions can also be placed in an evolutionary framework. For instance, a man may experience hypoactive sexual desire towards a woman with whom he has mated several times over several years and may yet experience heightened sexual desire with other women. This may be attributed to a male adaptation that has evolved to motivate men to seek multiple partners. Moving on to another example, if a man is having sex with a woman who is mated to another man, premature ejaculations may be an adaptation that helps him avoid detection of the intercourse from a jealous partner (see Gallup and Burch 2004).

In the same vein, men experience sexual arousal when exposed to cues of female infidelity (Pham and Shackelford 2014). In particular, men experience intense desire to have sex with their partner and sometimes even force sex top their partner, when they suspect or discover that she committed infidelity (Goetz et al. 2008). Thus, men may experience situational hypoactive sexual desire when their partners do not exhibit clues of infidelity, a situation which can be easily reverted.

\section{Conclusion}

The idea that the roots of sexual dysfunctions lie in the evolutionary history of our species is not new (e.g., Hong 1984), but the reasons why selection forces have allowed such variation in sexual functioning have not been identified. One explanation for this is that scholars tend to assume that the mating patterns prevailing in modern post-industrial societies such as free mate choice were also prevalent in ancestral human societies during the period of human evolution (Apostolou 2014). This assumption makes the high prevalence of sexual dysfunctions enigmatic. The present paper addresses this shortcoming by incorporating systematic anthropological and historical evidence that enables the reconstruction of the ancestral human condition.

This evidence indicates that in ancestral human societies mate choice was regulated and evolutionary pressures on men to sexually satisfy their partners had been much weaker than they are now in post-industrial societies (Apostolou 2014). 
This makes the high prevalence of sexual dysfunctions in men in the latter societies much less puzzling. In particular, by using existing evolutionary models, this paper has argued that ancestral neutrality can account for part of the prevalence of premature ejaculation and erectile dysfunction, while balancing selection can account for part of the prevalence of hypoactive sexual desire. Polygenic mutation can account for the minority of more severe cases of sexual dysfunctions. These models potentially account for a considerable part of the variation in sexual functioning, with age effects and medical and psychopathological factors accounting for the rest of the prevalence of sexual dysfunctions in men. Overall, new directions for studying and treating sexual dysfunctions need to emerge based on insights derived from the evolutionary framework.

Acknowledgments The author would like to thank Georgia Kapitsaki, Michael N. Pham and two anonymous reviewers for their constructive criticism and useful comments which enabled the improvement of this work.

\section{References}

Association, A. P. (2013). DSM-5. Washington: American Psychiatric Publishing.

Apostolou, M. (2007). Sexual selection under parental choice: the role of parents in the evolution of human mating. Evolution and Human Behavior, 28, 403-409.

Apostolou, M. (2010). Sexual selection under parental choice in agropastoral societies. Evolution and Human Behavior, 31, 39-47.

Apostolou, M. (2012). Sexual selection under parental choice: evidence from sixteen historical societies. Evolutionary Psychology, 10, 504 518.

Apostolou, M. (2013). The evolution of rape: the fitness benefits and costs of a forced-sex mating strategy in an evolutionary context. Aggression and Violent Behavior, 18, 484-490.

Apostolou, M. (2014). Sexual selection under parental choice: the evolution of human mating behaviour. Hove: Psychology Press.

Apostolou, M. (2015). Understanding the prevalence of sexual dysfunctions in women: an evolutionary perspective. Adaptive Human Behavior and Physiology: Advance Online Publication.

Bancroft, J. (2009). Human sexuality and its problems (3rd ed.). Edinburgh: Elsevier.

Barnes, T., \& Eardley, I. (2007). Premature ejaculation: the scope of the problem. Journal of Sex and Marital Therapy, 33, 151-170.

Barrantes-Vidal, N. (2004). Creativity and madness revisited from current psychological perspectives. Journal of Consciousness Studies, 11, $58-78$.

Basson, R., \& Schultz, W. (2007). Sexual sequelae of general medical disorders. Lancet, 369, 409-429.

Bellwood, P. (2004). First farmers: the origins of agricultural societies. New York: Blackwell.

Bergen, R. K. (1996). Wife rape: understanding the response of survivors and service providers. In C. Renzett \& J. Edleson (Eds.), Sage series on violence against women. California: Sage.

Brooks, R., Hunt, J., Blows, M. W., Smith, M. J., Bussière, L. F., \& Jennions, M. D. (2005). Experimental evidence for multivariate stabilizing sexual selection. Evolution, 59, 871-880.
Broude, G. J. (1980). Extramarital sex norms in cross-cultural perspective. Cross-Cultural Research, 15, 181-218.

Broude, G. J., \& Green, S. J. (1983). Cross-cultural codes on husbandwife relationships. Ethnology, 22, 263-280.

Buss, D. M. (2003). The evolution of desire: Strategies of human mating (2nd ed.). New York: Basic Books.

Buss, D. M., \& Schmitt, D. P. (1993). Sexual strategies theory: an evolutionary perspective on human mating. Psychological Review, 100, 204-231.

Carson, C., \& Guun, K. (2006). Premature ejaculation: definition and prevalence. International Journal of Impotence Research, 18, S5S13.

Carvalheira, A., Træen, B., \& Štulhofer, A. (2014). Correlates of men's sexual interest: a cross-cultural study. Journal of Sexual Medicine, $11,154-164$.

Carvalho, J., \& Nobre, P. (2011). Predictors of men's sexual desire: the role of psychological, cognitive-emotional, relational, and medical factors. Journal of Sex Research, 48, 254-262.

Caskurulu, T., Tasci, A. I., Sahinkanat, T., \& Ergenekon, E. (2004). The etiology of erectile dysfunction and contributing factors in different age groups in Turkey. International Journal of Urology, 11, 525529.

Chagnon, N. A. (1992). Yanomamo (4th ed.). Fort Worth: Harcourt Brace Jovanovich College Publishers.

Cordain, L., Gotshall, R. W., \& Eaton, S. B. (1998). Physical activity, energy expenditure and fitness: an evolutionary perspective. International Journal of Sports Medicine, 19, 328-335.

Corona, G., Mannucci, E., Petrone, L., Giommi, R., Mansani, R., Fei, L., Forti, G., \& Maggi, M. (2004). Psycho-biological correlates of hypoactive sexual desire in patients with erectile dysfunction. International Journal of Impotence Research, 16, 275-281.

Cowden, C. R., \& Bradshaw, S. D. (2007). Religiosity and sexual concerns. International Journal of Sexual Health, 19, 15-24.

Dunn, K. M., Jordan, K., Croft, P. R., \& Assendelft, W. J. (2002). Systematic review of sexual problems: Epidemiology and methodology. Journal of Sex and Marital Therapy, 28, 399-422.

Eaton, S. B. (2006). The ancestral human diet: what was it and should it be a paradigm for contemporary nutrition? Proceedings of the Nutrition Society, 65, 1-6.

Ember, C. R. (1978). Myths about hunter-gatherers. Ethnology, 17, 439448.

Fasolo, B. C., Mirone, V., Gentile, V., Parazzini, F., \& Ricci, E. (2005). Premature ejaculation: Prevalence and associated conditions in a sample of 12,558 men attending the andrology prevention week 2001 - a study of the Italian Society of Andrology (SIA). Journal of Sex Research, 2, 376-382.

Figueredo, A. J., Gladden, P. R., Vásquez, G., Wolf, P. S. A., \& Jones, D. N. (2009). Evolutionary theories of personality. In P. J. Corr \& G. Matthews (Eds.), Cambridge handbook of personality psychology: part IV. Biological perspectives (pp. 265-274). Cambridge, UK: Cambridge University.

Fisher, H. (1998). Lust, attraction, and attachment in mammalian reproduction. Human Nature, 9, 23-52.

Fischer, M. E., Vitek, M. E., Hedeker, D., Henderson, W. G., Jacobsen, S. J., \& Goldberg, J. (2004). A twin study of erectile dysfunction. Archives of Internal Medicine, 164, 165-168.

Fugl-Meyer, A. R., \& Fugl-Meyer, K. S. (1999). Sexual disabilities, problems and satisfaction in 18-74 year old Swedes. Scandinavian Journal of Sexology, 3, 79-105.

Gangestad, S. W., \& Simpson, J. A. (2000). The evolution of human mating: trade-offs and strategic pluralism. Behavioral and Brain Sciences, 23, 573-644.

García-Dorado, A., Caballero, A., \& Crow, J. F. (2003). On the persistence and pervasiveness of a new mutation. Evolution, $57,2644-2646$ 
Giles, J. (2008). The nature of sexual desire. New York: University Press of America.

Goetz, A. T., Shackelford, T. K., \& Camilleri, J. A. (2008). Proximate and ultimate explanations are required for a comprehensive understanding of partner rape. Aggression and Violent Behavior, 13, 119-123.

Goody, J., \& Tambiah, S. J. (1973). Bridewealth and Dowry. Cambridge: Cambridge University Press.

Gray, P. B. (2013). Evolution and human sexuality. American Journal of Physical Anthropology, 57, 94-118.

Gray, P. B., \& Garcia, J. R. (2013). Evolution and human sexual behavior. Cambridge: Harvard University Press.

Gallup, G. G., \& Burch, R. L. (2004). Semen displacement as a sperm competition strategy in humans. In T. Shackelford \& N. Pound (Eds.), Sperm competition in humans: classic and contemporary readings (pp. 245-254). New York: Springer.

Gurven, M., \& Kaplan, H. (2007). Hunter-gatherer longevity: cross-cultural perspectives. Population and Development Review, 33, 321-365.

Hartmann, U. (2007). Depression and sexual dysfunction. Journal of Men's Health and Gender, 4, 18-25.

Hawkes, K., \& Paine, R. (2006). The evolution of human life history. Santa Fe: School of American Research.

Hong, L. K. (1984). Survival of the fastest: On the origin of premature ejaculation. Journal of Sex Research, 20, 109-122.

Janssen, P. K., Bakker, S. C., Réthelyi, J., Zwinderman, A. H., Touw, D. J., Olivier, B., \& Waldinger, M. D. (2009). Serotonin transporter promoter region (5-HTTLPR) polymorphism is associated with the intravaginal ejaculation latency time in Dutch men with lifelong premature ejaculation. The Journal of Sexual Medicine, 6, 276-284.

Jern, P., Santtila, P., Johansson, A., \& Sandnabba, N. K. (2009). Genetic and environmental effects on the continuity of ejaculatory dysfunction. BJU International, 105, 1698-1704.

Jern, P., Santtila, P., Witting, K., Alanko, K., Harlaar, N., Johansson, A., von der Pahlen, B., Varjonen, M., Vikström, N., Ålgars, M., \& Sandnabba, K. (2007). Premature and delayed ejaculation: genetic and environmental effects in a population-based sample of Finnish twins. The Journal of Sexual Medicine, 4, 1739-1749.

Kaplan, M. S., \& Kruger, R. B. (2010). Diagnosis, assessment and treatment of hypersexuality. Journal of Sex Research, 47, 181-198.

Keller, M. C., \& Miller, G. F. (2006). Resolving the paradox of common, harmful, heritable mental disorders: which evolutionary genetic models work best? Behavioral and Brain Sciences, 29, 385-452.

Klusman, D. (2002). Sexual motivation and the duration of partnership. Archives of Sexual Behavior, 31, 275-287.

Lambert, N. M., Negash, S., Stillman, T. F., Olmstead, S. B., \& Fincham, F. D. (2012). A love that doesn't last: Pornography consumption and weakened commitment to one's romantic partner. Journal of Social and Clinical Psychology, 31, 410-438.

Laumann, E. O., Nicolosi, A., Glasser, D. B., Paik, A., Gingell, C., Moreira, E., \& Wang, T. (2005). Sexual problems among women and men aged 40-80 y: prevalence and correlates identified in the Global Study of Sexual Attitudes and Behaviors. International Journal of Impotence Research, 17, 39-57.

Laumann, E. O., Paik, A., \& Rosen, R. C. (1999). Sexual dysfunction in the United States: prevalence, predictors and outcomes. Journal of the American Medical Association, 281, 537-544.

Lee, R. B., \& Devore, I. (1968). Man the hunter. New York: Aldine.

Lewis, R. W., Fugl-Meyer, K. S., Bosch, R., Fugl-Meyer, A. R., Laumann, E. O., Lizza, E., \& Martin-Morales, A. (2004). Epidemiology/risk factors of sexual dysfunction. The Journal of Sexual Medicine, 1, 35-39.

Liu, M. (2002). Influences of sexual performance anxiety on erectile dysfunction. Chinese Journal of Clinical Psychology, 10, 47-49.

Longley, A. J. (2001). Depression is an adaptation. Archives of General Psychiatry, 58, 1085-1086.

Loudon, J. (1998). Potential confusion between erectile dysfunction and premature ejaculation: an evaluation of men presenting with erectile dysfunction at a sex therapy clinic. Journal of Sex and Marital Therapy, 13, 397.

McCabe, M. P. (2005). The role of performance anxiety in the development and maintenance of sexual dysfunction in men and women. International Journal of Stress Management, 12, 379-388.

Masters, W. H., \& Johnson, V. E. (1970). Human sexual inadequacy. Boston: Little Brown.

Mealey, L. (1995). The sociobiology of sociopathy: an integrated evolutionary model. Behavioral and Brain Sciences, 18, 523-599.

Meltzer, M. (1993). Slavery: a world history. Boston: Da Capo Press.

Morris, R., \& Watson, T. (2011). Positively versus negatively frequencydependent selection. Advances in Artificial Life, 5778, 77-84.

Mussachio, N. H., Hatrich, M. H., \& Garofalo, R. (2006). Erectile dysfunction and Viagra use: What's up with college-age males. Journal of Adolescent Health, 39, 452-454.

Pham, M. N., \& Shackelford, T. K. (2014). Human sperm competition: a comparative evolutionary analysis. Animal Behavior and Cognition, $1,410-422$.

Plomin, R., DeFries, J. C., Knopik, V. S., \& Neiderhiser, J. M. (2012). Behavioral genetics. New York: Worth Publishers.

Polimeni, J., \& Reiss, J. P. (2002). How shamanism and group selection may reveal the origins of schizophrenia. Medical Hypotheses, 58, 244-248.

Richters, J., Grulich, A. E., de Visser, R. O., Smith, A. M., \& Rissel, C. E. (2003). Sex in Australia: Sexual difficulties in a representative sample of adults. Australian and New Zealand Journal of Public Health, 27, 164-170.

Russell, D. E. H. (1990). Rape in marriage (Rev.ed.). Indianapolis: Indiana University Press.

Safarinejad, M. R. (2011). Relationship between premature ejaculation and genetic polymorphisms of the dopamine transporter gene (SLC6A3). BJU International, 108, 292-296.

Santilla, P., Jern, P., Westberg, L., Walum, H., Pedersen, C. T., Eriksson, E., \& Kenneth Sandnabba, N. (2010). The dopamine transporter gene (DAT1) polymorphism is associated with premature ejaculation. The Journal of Sexual Medicine, 7, 1538-1546.

Shires, A., \& Miller, D. (1998). A preliminary study comparing psychological factors associated with erectile dysfunction in heterosexual and homosexual men. Journal of Sex and Marital Therapy, 13, 37 49.

Simons, J., \& Carey, M. P. (2001). Prevalence of sexual dysfunctions: Results from a decade of research. Archives of Sexual Behavior, 30, $177-219$.

Sipos, A., Rasmussen, R., Harrison, G., Tynelius, P., Lewis, G., Leon, D. A., \& Gunnell, D. (2004). Paternal age and schizophrenia: a population based cohort study. British Medical Journal, 329, 1070-1075.

Stearns, S. C. (1992). The evolution of life histories. New York: Oxford University Press.

Stephens, W. N. (1963). The family in cross-cultural perspective. New York: Holt, Rinehart \& Winston.

Strassberg, D. S., Mahoney, J. M., Schaugaard, M., \& Hale, V. E. (1990). The role of anxiety in premature ejaculation: a psychophysiological model. Archives of Sexual Behavior, 19, 251-257.

Thornhill, R., \& Palmer, C. T. (2000). A natural history of rape: Biological bases of sexual coercion. Cambridge: The MIT Press.

Toates, F. (2014). Sexual desire: the enigmatic urge. Cambridge: Cambridge University Press.

Tooby, J., \& Cosmides, L. (1990). The past explains the present. Ethology and Sociobiology, 11, 375-424.

Trivers, R. L. (1972). Parental investment and sexual selection. In B. Campbell (Ed.), Sexual selection and the descent of man: 18711971 (pp. 136-179). Chicago: Aldine.

Wilson, D. S. (1994). Adaptive genetic variation and human evolutionary psychology. Ethology and Sociobiology, 15, 219-235.

Wilson, D. R. (1998). Evolutionary epidemiology and manic depression. The British Journal of Medical Psychology, 71, 367-395. 
Wilt, J., Oehlberg, K., \& Revelle, W. (2011). Anxiety in personality. Personality and Individual Differences, 50, 987-993.

Wincze, J. P., \& Carey, M. P. (2001). Sexual dysfunction: a guide for assessment and treatment (2nd ed.). New York: The Guilford Press.

Wright, P. J. (2013). US males and pornography, 1973-2010: Consumption, predictors, correlates. Journal of Sex Research, 50, $60-71$.

Zhu, L., Mi, Y., You, X., Wu, S., Shao, H., Dai, F., Peng, T., Qin, F., \& Feng, N. (2013). A meta-analysis of the effects of the 5-
Hydroxytryptamine transporter gene-linked promoter region polymorphism on susceptibility to lifelong premature ejaculation. PLOS ONE, 8, e54994.

Zion, I. Z. B., Tessler, R., Cohen, L., Lerer, E., Raz, Y., Bachner-Melman, R., Gritsenko, I., Nemanov, L., Zohar, A. H., Belmaker, R. H., Benjamin, J., \& Ebstein, R. P. (2006). Polymorphisms in the dopamine D4 receptor gene (DRD4) contribute to individual differences in human sexual behavior: Desire, arousal and sexual function. Molecular Psychiatry, 11, 782-786. 